\title{
The Different Implementations of Building Positive Impression in the ELT Articles
}

\author{
Agung Budi Kurniawan ${ }^{1}$, Warsono ${ }^{2}$, Djoko Sutopo ${ }^{3}$, Sri Wuli Fitriati ${ }^{4}$ \\ \{agungbudi430@yahoo.co.id ${ }^{1}$, warsono1103@gmail.com² , djoko.sutopo@mail.unnes.ac.id ${ }^{3}$, \\ SriWuli.Fitriati@mail.unnes.ac.id $\left.{ }^{4}\right\}$ \\ ${ }^{1}$ STKIP PGRI Pacitan, Indonesia \\ ${ }^{2,3,4}$ Graduate School, Universitas Negeri Semarang, Indonesia
}

\begin{abstract}
One factor that influences the successfulness of published articles was a positive impression. It could attract the editors', reviewers', and readers' attention and appreciation. In this study, the researchers analyzed the different implementation of seven articles to build a positive impression based on Appraisal study. The articles were chosen through purposive sampling. It was analyzed by using the coding and interpreting technique. The findings show that every article had different implementation that comprised the exploration of the process and product, logical explanation of cause and effect, proposition of different reality between idealism and fact, pointing the trigger of finding, proposition of benefits, successfulness argumentation, and the explanation of method of collecting data. The results were beneficial to be applied as an Interpersonal technique to make the article is accepted in a publication because in the era of the online system, the publication requisites become higher.
\end{abstract}

Keywords: Positive Impression, ELT, Articles, Interpersonal

\section{INTRODUCTION}

Communication and interaction in the written text are social practices that need serious attention, training, and evaluation. It is as significant as the spoken text. The interaction of written text could be categorized as a risk-taking because it is an indirect interaction. The opportunity of clarification could be littler than the spoken interaction. Writing is a social practice that carries communication as a reflection of the writers' intention [1]. Because of its important rule, writing practice gives significant rule in the meaning transfer in communication. It is a comprehensive manifestation of a writer's language competence and logical thinking [2]. The writing practice is not as simple as arranging language by following the grammatical rules. It has a complex system as the representation of the writers' ideas. One of the systems of writing for communication is performance and impression. Written text is not only about proposing the idea, but also it is about the technique of communication to attract the readers' attention, sympathy, and trust. The positive impression was proven the key point to gain them all in the written communication.

One of the writing styles that could be employed to build a positive impression is persuasive writing. The high quality of persuasive writing should deal with more than one item and reflect 
the authentic and real-world [3]. The persuasive writing style could reach many aspects which means it was flexible. The application of persuasive writing to build a positive impression is based on the real world means it is not an artificial text. Persuasive writing is intended for real communication. The criteria for ideal persuasive writing comprise productivity, syntactic complexity, lexical complexity, and persuasive quality [4]. The persuasive writing is similar to other genres whose specific rule, implementation, and purpose. In this research, some of the findings applied the persuasive purpose indirectly. Based on the findings, the persuasive implication tends to build a positive impression to conduct personal approach. It tried to get closer personal interaction so that getting the readers' personal attention and sympathy was the basic purpose of persuasive writing practice to build a positive impression.

In the wider area, persuasive writing could be studied for academic purpose. It could give good skill of personal communication to students. The study of quantitative persuasive writing could be carried out through experimental design [5]. The persuasive writing offers good communication skill for students or practitioners to write an article for publication. The article for publication needs the skill of persuading the readers to give great attention to the text.

The second type of writing that could be applied to build a positive impression is argumentative writing which was also found in this research. The criteria of argumentative writing were relevance, clarity, logicality, profundity, and flexible [6]. The whole criteria were also found being applied by some authors in this research. In the term of relevance, the authors need to propose the material which supports their main argumentation in the adequate quantity and frequency. In the clarity criteria, the language must be easy to be understood that the authors have to recognize the education level and character of the readers. In the logicality criteria, the material must make sense. In the term of profundity, the authors should give deep review. In the flexible criteria, the authors were recommended to use popular vocabulary and idiom for the readers. The findings show that the argumentative writing style to build a positive impression was different from the persuasive since the argumentative writing style did not concern on developing close personal approach. In argumentative writing, the authors proposed the empiric evident so that they let the readers give justification. It requires high effort.

Besides, the personal language character needs to be managed in writing an article for publication. Even in the academic area, students need to study the use of language for communication [7]. The authors need to adapt their language character with the readers' personality. The success of building a positive impression in the written text could be the entry point to gain excellent indirect communication. The finding of this research showed that it is not only the quality of writing material but also how to present the material of the writing.

In this research, the researchers proposed one research question, which is "how is the different implementation of building a positive impression in the seven ELT articles?". The objective of this study is "to reveal the different personal orientation in building a positive impression in the seven ELT articles".

\section{METHOD}

The design of this research was qualitative. It means this research concern on describing the meaning of the object. The meaning was based on fact and evidence. The qualitative design deals with meaning and language, which is not a matter of subjective opinion [8]. The object was seven articles in English Language Teaching field study that were published by journal publishers. They were selected by applying the purposive sampling technique. The instrument comprises the lexical list and Interpersonal Meaning of Attitude [9]. The technique of collecting data was observation. In analysing the data, this research applied the schema of describing, 
classifying, and connecting [8]. In the first step of describing, researchers described the clue of lexical which was potential as the fixed finding. The field action was collecting the phrases. In the second step of classifying, the collected phrases were checked with the supporting evidence. In this step, it was the final decision whether the data could be taken or eliminated. In the last step of connecting, the Interpersonal Meanings were described by connecting the phrases and the supporting evidences. The analysis of every object was separated from each other because it was almost impossible to construct the holistic analysis. Every finding has different context of use.

\section{RESULT AND DISCUSSION}

The findings and discussion covered the data of the seven articles or objects. Every object has different implementation of the positive impression. The finding and analysis were presented simultaneously one by one.

In the article or object 1 , the implementation was to cover the research process weaknesses by inviting readers to see the process and the product equally. The positive impressions were honest, fair, and objective. The authors admitted that their product was imperfect. The data of the article 1 showed that the quantitative error number was made by the learners. Meanwhile, it was the product of the research as one of the main objectives of the study. On the other hand, the fact did not decrease the authors' confident to inform it totally. They did not manipulate the information. On the other hand, the explanation of the process behind the product was also presented comprehensively. The processes were placed as one benefit of the research. The imperfect product of the use of lexical bundles indicated that the research was existed. Implicitly, the argumentation was that the imperfect product was one of the indicators that the research process was existed and not being manipulated. The authors would like to argue that the process also needs to be appreciated as important as the product. In fact, the explanation did not stop on giving the argumentation. The program for the future progress proposed the desire for the improvement. The implementation represented the authors' professionalism in conducting and communicating the research report for publication. They could admit the research weakness, but it was also success to keep the good impression and credibility of the scientific value. The finding was contrast with the concept of building impression through persuasive essays in which the authors can select the favorable evidence, play emotion, and used the style of persuasive [10]. The difference was on the background. The finding of argumentation was based on the proposition of scientific evidence, and it had no manipulation purpose. It let the readers to justify it objectively. Meanwhile, the persuasive technique tends to conduct personal approach to readers so that they could agree with the authors' writing.

The next finding and analysis belong to the article or object 2 . The implementation was to propose the logical relationship of cause and effect especially to emphasize the consequence of a fact. The authors tried to show that a result or fact was not taken for granted or being happened by accident. The ability to understand and synthesis a problem was crucial in the writing literacy [11]. In this research, the authors would like to propose that the finding has basic of background, problem, and purpose as the representation of their ability to synthesis material in the text. The cause in the article 2 was the indication of the students' development in the writing from the English source. Then, it was followed by the effect or result that it needs to be investigated carefully. The flow of the information holds the successful key of information. The second was the quantity of the information which was "enough". The information of the cause and effect were "balance" so that it assisted readers to understand easily. The implementation of the explanation could also be categorized as an effort to build objective impression in concluding 
the effect or consequence of a cause. They would like to imply a message that the cause and effect was a common phenomenon, but it still fulfilled the scientific requisites. In this case, it also tried to imply the message that anyone who was in the authors' position would conclude the similar thing.

In the article or object 3, the implementation was to show the difference between the ideal concepts with empiric fact. There were two groups as the object of the authors' target of the study. The ideal concept was that both of group 1 and 2 can usefully be taught respect. In fact, the authors admitted indirectly that the empiric fact propose the large different between the group 1 and 2. In this case, the authors also tried to be honest with the empiric data. They did not want to manipulate the empiric condition. They realized the idealism concept had not been in line with the empiric data. In one study, the technique to be honest to communicate the idea or data was to put all facts together and specify the material before being written [12]. It also implied a message that not all objectives and hypothesis must be answered or proven successfully. The honest value is as important as the research successfulness. The conclusion of the object 3 implementation was that negative result did not represent the negative impression. It sometimes depends on the manner how to communicate the material of the article report. It also depends on the communication skill in the written text. The unexpected material could still build positive impression as long as it contains honest and scientific value. The manipulation technique was very fragile to be applied in the research report. In this case, the authors' decision was very important in "how to report the research result in the written publication".

In the article 4, the implementation was to propose a trigger to point a detail finding. The authors gave suggestion to readers to see a table in order to get the detail explanation. It was a trigger to encourage readers to observe the table carefully. It seems a bridge to point a certain reference. The other implementation was being a hedge to avoid the impression of "forcing" readers to believe and agree with the content of the article. It was why they suggested them to see the table. The special case was that it concerned on the special reference in the table. The authors would like readers to observe the data presented, and concluded it by themselves. In fact, the expectation was that the conclusion would be similar with the authors' ideas. It was actually a high level of communication strategy to build positive impression, but it was fragile to fail. In order to apply the technique, the authors must have prepared the data of reference in detail very well. The lack of quantity and quality of the finding presentation will disturb the trustworthiness value of the article. In writing an argumentative essay, the writers should plan the materials and activities before writing and prepare the effective schema [13]. In this implementation, the technique of writing was not enough, but the validity and reliability of the finding determined the successfulness of the positive impression value.

In the article or object 5, the implementation was to explain a sequence of benefit of a recommended method. The method referred to "a complex analysis" method. It was claimed to give benefit of postmodifers. The proposition of the benefit actually also represented the article positive value itself. It was caused that the method of the article was still in line with the method that was proposed. It was a technique to promote the article positive value indirectly. The authors encouraged the readers to focus on the description of the "complex analysis" first. And, then, it turned slowly to discuss the article method. The implementation could be categorized had persuasive purpose which is to try to change the readers' point of view [14]. The strength of the implementation was precise of quantity discussion. The quantity of the method of the proposition was larger than the article method. The authors tried to avoid getting impression that they promoted the article method directly. The technique actually had minimum risk because it did not present the finding of the research. If the positive value got lack of trustworthiness, it did not 
give significant justification of readers. Most of the readers tend to be observe the background, and finding and analysis result directly when reading an article.

In the next material of the object 6 , the implementation was to build positive impression of the research successfulness based on the personal view point or perspective. The authors argued that the material of English post modification gave variation in the structure. Then, It presented a table for the detail or complete supporting data. There were two sides based on the statement. The main message was the authors' personal justification to their research successfulness. The second was that they presented the table as the basis of the statement. The combination of the statement and the table were presented in a good sequence. The personal viewpoint was proposed directly because it needs a strong statement to announce the research result description. In this finding, the authors were predicted had observed the whole results carefully before stating it directly. The statement represented the high confidence. The finding was in line with one of the academic writing characteristics which are clear point of view. In the academic writing process and result, the main goal is not only to present the detail facts of summaries, but the authors have to show their ideas and argumentation to the fact clearly [14]. It could be concluded that presenting or summarizing findings or facts was not enough in the scientific article. At least, the author must give personal perspective clearly. It was recommended to separate the findings and the authors' viewpoint directly.

The last finding was found in the article or object 7. The implementation was to admit and explain the sequence of action of collecting data based on a previous study. The authors explained that the main actions were to integrate and relate the findings into a manageable unit which was based on a previous study. Then, they explained every step of the action in detail. It was not only to explain but also to admit the basis of the technique. In fact, they also proposed development. The other implementation was to be honest to admit that the research quality was the combination of the previous study and the authors' work result. The other implementation was to propose the strong basis of scientific method. It was a simple admission and explanation, but it could gain the readers' high respect. The other key point of successful was the quality of the previous study because it had been proven ever applied successfully. One additional technique that could be combined with the finding was mapping. Mapping means organizing ideas, changing the general topic into one perspective in order to make classification on the aspect that was related with the topic or title [15]. The academic or scientific writing of a text was recommended to be practiced and corrected more than once time. It is difficult to result an ideal text through one moment of writing. The other important thing was the preparation and mapping of the material. The good impression was also viewed from the text information structure.

\section{CONCLUSION}

Positive impression of an article was the entry point to get readers' deep attention. It could contribute to increasing the article credibility in front of the readers. The main point was not only the quality of the material of the research result, ideas, or concept, but also it is about how to communicate the material of the article. The authors were not recommended for being selfish for their idealism. It means the authors must correlate the idealism with the readers' passion. The authors must understand the readers' character, level of education, the scope of the study, and their expectation to the article. The authors must place themselves to serve or proposed scientific information to readers. So, authors must place their idealism in line with the readers' passion. They should place the readers as the partner. The authors were not recommended to place themselves as superior than the readers but in equal position. The communication 
strategies determine the quality of the research articles too. It was about how to reach the readers' mind and feeling. This research would be beneficial for the development of scientific or academic writing for publication. The writing study for publication always develops because science also always develops.

\section{REFERENCE}

[1] H. Tan and W. B. Eng, "Metadiscourse Use in the Persuasive Writing of Malaysian Undergraduate Students,” English Lang. Teach., vol. 7, no. 7, pp. 26-39, 2014.

[2] Y. Zhang, "A Contrastive Study on the Application of Mind Maps in Argumentative Writing Instruction for EFL Learners," English Lang. Teach., vol. 11, no. 12, pp. 93-100, 2018.

[3] P. Brett and D. Thomas, "Discovering Argument: Linking Literacy, Citizenship Education, and Persuasive Advocacy," J. Soc. Sci. Educ., vol. 13, no. 4, pp. 66-77, 2014.

[4] H. M. Brown, A. M. Johnson, R. E. Smyth, and J. O. Cardy, "Exploring the Persuasive Writing Skills of Students with High-Functioning Autism Spectrum Disorder," Res. Autism Spectr. Disord., vol. 8, pp. 1482-1499, 2014.

[5] O. H. Sayed, "Developing Business Management Students' Persuasive Writing Through Blog-based Peer-Feedback,” English Lang. Teach., vol. 3, no. 3, pp. 54-66, 2010.

[6] Z. Pei, C. Zheng, M. Zhang, and F. Liu, "Critical Thinking and Argumentative Writing: Inspecting the Association among EFL Learners in China," English Lang. Teach., vol. 10, no. 10, pp. 31-42, 2017.

[7] K. Wolbers, H. Dostal, S. Graham, L. Branum-Martin, J. Kilpatrick, and R. Saulsburry, "Strategic and Interactive Writing Instruction: An Efficacy Study in Grades 3-5," J. Educ. Dev. Psychol., vol. 8, no. 1, pp. 99-117, 2018.

[8] I. Dey, Qualitative Data Analysis: A User-Friendly Guide for Social Scientists. New York: Taylor \& Francis, 2005.

[9] J. R. Martin and P. R. R. White, The Language of Evaluation Appraisal in English. New York: Palgrave Macmillan, 2005.

[10] G. H. Jr., "Teaching Argument for Critical Thinking and Writing: An Introduction," English J., vol. 6, pp. 24-32, 2010.

[11] R. Zhao and A. Hirvela, "Undergraduate ESL Students' Engagement in Academic Reading and Writing in Learning to Write a Synthesis Paper," Read. a Foreign Lang., vol. 27, no. 2, pp. 219-241, 2015.

[12] H. M. El-daly, "Cross-Cultural and Cognitive Variation in the Persuasive Writing of Arabic and Spanish Speakers: A Qualitative Analysis," Int. J. Acad. Res. Bus. Soc. Sci., vol. 2, no. 7, pp. 51-81, 2012.

[13] L. Mingli, "Research on Three-part Argumentative Writings for English Majors in China," English Lang. Teach., vol. 5, no. 7, pp. 140-148, 2012.

[14] A. Whitaker, Academic Writing Guide. Bratislava, Slovakia: City University of Seattle, 2010.

[15] E. S. Wahyuni, "The Strategy of Using Persuasive Essay in English for Medical Academic Writing,” J. Sos. Hum., vol. 7, no. 1, pp. 1-19, 2017. 